\title{
The use of thermodynamic characteristics when selecting fire retardants
}

\author{
Elena Pokrovskaya and Feodor Portnov* \\ Moscow State University of Civil Engineering, Jaroslavskoe Shosse 26, \\ Moscow, Russian Federation
}

\begin{abstract}
In the present study we consider the modification of wood by phosphites to reduce flammable properties. We define thermodynamic parameters of modified wood surface. The study explains high values of free surface energy while studying the surface structure and the surface layer of modified wood. Based on the findings, the possibility of thermodynamic optimization of modifiers upon development of protective compositions is shown.
\end{abstract}

\section{Keywords.}

Chemical modification, thermodynamic characteristics, phosphites, thermodynamic optimization, fire resistance

\section{Introduction}

Modification is an effective way to improve performance of building materials, including wood [1-4]. There are mechanical, thermal and chemical modification. Technologically the simplest and most available is surface chemical modification, which allows to reduce fire risk of structures, hydrophilic properties, to create a high biocorrosion resistance. The effectiveness of surface chemical modification is determined by the selection of a modifier, which reacting with wood components causes the durability of the acquired performance properties [5-6].

For effective modification the selection of modifier is the most important and difficult task. It was natural, that with surface modification, surface properties affect the efficiency of the modification process. Energy properties are characterized by changes in the following thermodynamic characteristics: the contact angle, the surface tension, and the change in Gibbs thermodynamic potential of the surface during the modification.

The surface energy intensity factor is surface tension [7]. The dynamic analysis of Gibbs thermodynamic potential of the modified surface is based on the combined I and II principles of thermodynamics [8-12].

$\Delta \mathrm{G}=\sigma \mathrm{dS}_{s p}+\mathrm{S}_{s p} \mathrm{~d} \sigma$

The study of surface modification of wood makes it possible to estimate in advance the effectiveness of surface layer modifiers using thermodynamic quantities $(\Delta \mathrm{G}, \sigma)$.

*Corresponding author: wastingtimefilmart@gmail.com 
Selecting the optimum characteristics allowing to estimate the efficiency of the substrate-modifier system is most rational for the selection of modifiers reducing the firehazardous properties of materials. That is the aim of the study.

To achieve the aim we set an objective to study the changes of the energy characteristics of the wood surface by the example of wood modification with phosphites, as well as the study of the thermodynamic optimization of modifiers reducing the fire-hazardous properties of materials.

\section{Research methods}

The following experimental methods are used to estimate the characteristics of modified wood.

The chemical analysis is performed using a Quanta 200 scanning microscope with an Apollo 40 attachment for element analysis using energy dispersive spectroscopy [13]. During the tests the phosphorus percentage in the samples of modified wood was estimated. The Quanta 200 microscope makes it possible to obtain high-definition images with magnification exceeding 100,000 times [14,15].

Data on the contact angle $\theta$ of modified wood samples are obtained by the method of a neutral drop on the Easy Drop DSA25S installation [16]. The Easy Drop installation consists of a sample holder, a liquid feeding gun mechanism and a high-definition camera. During the tests, the mechanism ensures the supply of a liquid drop and the camera provides a fixation of the moment of liquid drop contact with the sample.

Quantachrome NOVA 4200e device [17] and the Brewer-Emmett-Teller (BET) method, which measures the mass of the gas adsorbed by the sample after degassing [18], are used to determine the specific surface of the initial and modified wood.

The valuation of the protective action of the composition is performed by the method determining the group of fire-rating effectiveness of fire retardant and by the method of experimental determination of the smoke-developed index of solids and materials [19].

\section{Results and discussion}

The determination of thermodynamic characteristics is carried out on samples of pine sapwood in size of $40 \times 40 \times 10 \mathrm{~mm}$, the moisture content of the samples is $8 \%$. The $20 \%$ solutions of phosphites (dimethylphosphite (DMP), diethylphosphite (DEP), dipropylphosphite (DPP), dibutylphosphite (DBP), diphenylphosphite (DFP)) are used as modifiers. The literature notes an increase in the fire resistance of wood when modifying it with the indicated modifiers [3-4].

The objective of the study is to determine the change in Gibbs thermodynamic potential of the modified wood surface depending on the modifiers of the surface layer, and also to determine the relationship of the energy characteristics to the physico-chemical properties of the modified samples.

The modifiers are applied on the sample surface in two layers at temperatures of $20-25^{\circ}$ $\mathrm{C}$, the amount of modifiers used is $300 \mathrm{~g} / \mathrm{m}^{2}$. To remove the excess amount of a modifier not reacting with the surface, the samples are extracted in Soxhlet apparatus (solvent acetone, water). The samples are dried in a drying oven at $40^{\circ} \mathrm{C}$ for 6 hours, after which the samples are placed in a desiccator over anhydrous $\mathrm{CaCl}_{2}$ and dried at $25^{\circ} \mathrm{C}$ for 7 days.

The degree of chemical interaction of the modifiers in the wood surface layer is determined by the percentage of phosphorus in the samples after extraction. The $\% \mathrm{P}$ data is shown in Table 1 for various modifiers. 
Table 1. The content of phosphorus in the wood surface layer.

\begin{tabular}{|c|c|c|c|c|c|}
\hline & \multicolumn{5}{|c|}{ Surface layer modifier } \\
\cline { 2 - 6 } & DMP & DEP & DPP & DBP & DFP \\
\hline $\begin{array}{c}\text { \%P of thermal } \\
\text { destruction }\end{array}$ & 2.87 & 3.57 & 2.6 & 2.65 & 2.45 \\
\hline
\end{tabular}

The surface tension $\sigma$ is determined by the neutral drop method $[9,10]$ at the EasyDrop installation and the corresponding software. The values $\mathrm{S}_{\mathrm{sp}}$ of wood samples are obtained using NOVA Chrome 2200 installation by the nitrogen sorption method $[16,17,18]$ (Table 2).

We obtain the dependence $\cos \theta=f(\sigma)$ of the contact angle on the standard surface tension of a drop of the aqueous ethanol solutions of various concentrations in the form of an averaged straight line using the EasyDrop installation.

Extending the line equation to $\cos \theta=1$, it is possible to determine the critical value of the surface tension $\sigma$, which is a characteristic of the surface energy of a surface unit (Table 2)

Table 2. The values $\sigma$ and $\mathbf{S}_{\mathrm{sp}}$ for different modifiers.

\begin{tabular}{|c|c|c|c|c|c|c|}
\hline & & \multicolumn{4}{|c|}{ Surface layer modifier } \\
\cline { 2 - 7 } & $\begin{array}{c}\text { Initial } \\
\text { wood }\end{array}$ & DMP & DEF & DPP & DBP & DFP \\
\hline $\begin{array}{c}\sigma^{\mathbf{3}} \\
10^{3}, \mathrm{~N} / \mathrm{m}\end{array}$ & 25.33 & 19.91 & 25.03 & 21.97 & 24.19 & 23.03 \\
\hline $\mathrm{S}_{\text {sp }}$ & 42.52 & 58.56 & 17.081 & 71.49 & 70.37 & 18.289 \\
\hline
\end{tabular}

The surface of modified wood samples is also studied by electronic microscopy using a scanning electron microscope JSM-840 [14, 15]. The images of modified wood surface with an increase of 300 times are shown in Figure 3.

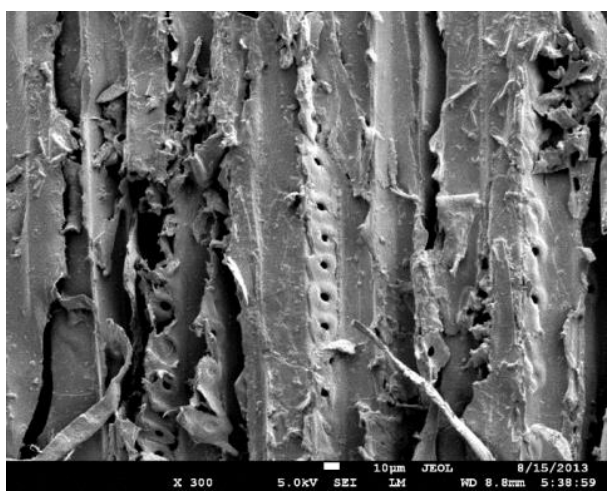

a

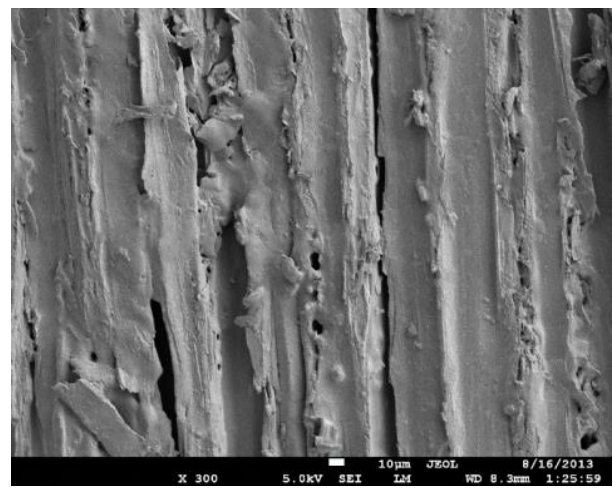

$\mathrm{b}$ 


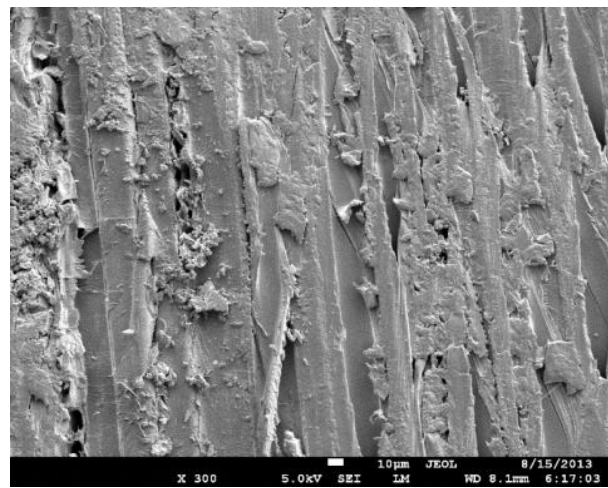

c

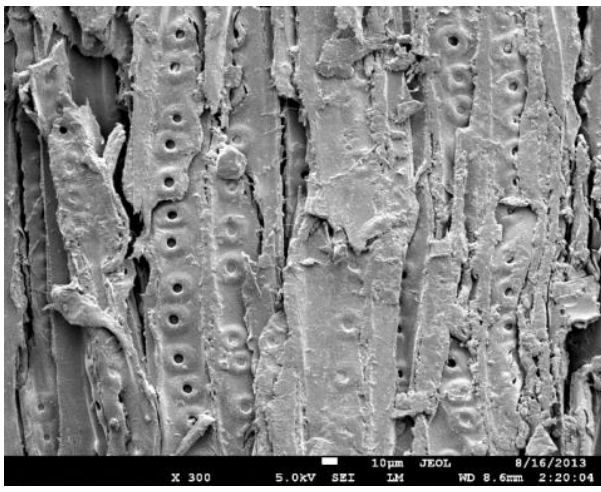

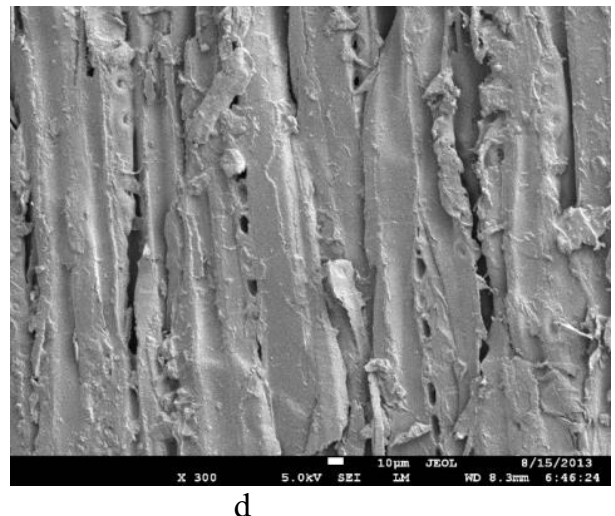

d

Figure 3. The electron microscope images of the wood surface, modified by dimethylphosphite (a), diethyl phosphite (b), dipropyl phosphite (c), dibutyl phosphite (d), diisopropylfluorophosphat (e), are obtained by electronic microscopy.

As can be seen from the obtained images, the wood surface varies depending on the value of the OR-group alkyl in phosphites. Using modifiers with the radicals $-\mathrm{C}_{3} \mathrm{H}_{7},-\mathrm{C}_{4} \mathrm{H}_{9}$, $-\mathrm{C}_{6} \mathrm{H}_{5}$, a complete covering of the wood surface takes place (dipropyl phosphite, dibutyl phosphite, diisopropylfluorophosphate).

Granting smaller radicals $-\mathrm{CH}_{3},-\mathrm{C}_{2} \mathrm{H}_{5}$, the oriented structure covering occurs and these modifiers (dimethylphosphite, diethyl phosphite) are characterized by the decrease of the specific surface, which is possible when covering the inner surface of the capillaries. By effective chemical modification, the walls of the capillaries are strengthened with a modifier, which results in pore size decrease and adsorption decrease.

Data on the smoke-forming capacity of wood, fire resistance $[19,20]$, and water vapor sorption [21-23] are obtained to assess the operational characteristics of the initial and modified wood (Table 3 ).

Table 3. Fire-hazardous properties and water vapor sorption of the initial and modified wood.

\begin{tabular}{|c|c|c|c|c|c|c|}
\hline & \multirow{2}{*}{$\begin{array}{c}\text { Initial } \\
\text { wood }\end{array}$} & \multicolumn{5}{|c|}{ Surface layer modifier } \\
\cline { 3 - 7 } & DMP & DEF & DPP & DBP & DFP \\
\hline$\Delta G, J$ & - & -12.68 & -14.5 & -4.94 & -6.97 & -10.16 \\
\hline$\Delta \mathrm{m} \%$ & 79.0 & 6.9 & 8.5 & 12.3 & 11.5 & 9.5 \\
\hline$a_{m}, \%$ & 421.1 & 215.8 & 155.5 & 221.9 & 193.4 & 163.52 \\
\hline
\end{tabular}




\begin{tabular}{|c|c|c|c|c|c|c|}
\hline $\mathrm{Dm}, \mathrm{m}^{2} / \mathrm{kg}$ & $\begin{array}{c}1010- \\
1050\end{array}$ & $450-470$ & $130-140$ & $640-680$ & $600-640$ & $740-780$ \\
\hline
\end{tabular}

Based on the obtained data of $\mathrm{S}_{\mathrm{sp}}$ and $\sigma$ (Table 2), Gibbs thermodynamic potential of the modified sample surface is calculated (Table 3 )

Table 3 shows that all values $\Delta \mathrm{G}<0$, this characterizes the inadvertent process of surface modification in these conditions. The most negative values of Gibbs thermodynamic potential variation of the modified wood surface are peculiar in case of using diethyl phosphite as a modifier, which largely interacts chemically with the lignincarbohydrate complex. The thermodynamic characteristics of the modification depend on the degree of chemical interaction of the substrate with the modifier.

\section{Conclusion}

With a surface modification of wood by $20 \%$ solutions of phosphites, an inadvertent chemical interaction of phosphorus-containing compounds with the wood substrate occurs. The greatest degree of chemical interaction is peculiar for diethyl phosphite, the smallest for diisopropylfluorophosphate. However, the wood surface is covering with modifier by diethyl phosphite modification. In addition, based on $\mathrm{S}_{\mathrm{sp}}$ data, we can conclude on the chemical modification of the internal part of the capillaries. Strengthening of the surface and capillary structure during chemical modification with phosphorus-containing compounds leads to the reduction of fire risk and smoke-forming ability of wood.

All the data obtained are correlated with the change in Gibbs thermodynamic potential $(\Delta \mathrm{G})$. The most negative values $\Delta \mathrm{G}$ characterize the surface of wood materials with lower values of fire risk.

Thus, we defined the method of thermodynamic optimization of wood with the aim to improve its operational characteristics, which allows to select the most effective modifiers by value $\Delta \mathrm{G}$. Based on the availability of the present method, we can talk about its great practical importance. The prospect of further study is the evaluation of the effectiveness of other classes of modifiers based on the present method.

\section{References}

1. E.N. Pokrovskaya, F.A. Portnov, A.A. Kobelev, D.A. Korolchenko, Fire and Explosion Safety, 10, 40-46 (2013)

2. A.A Stenin, Construction - the formation of the environment of life, 553-559 (2013)

3. V.A. Shamaev, International Scientific and Technical Conference "Modern Problems of Mechanical Wood Technology", 11-17 (2010)

4. E.U. Tariva, VI International Scientific and Technical Conference "Actual problems of construction and construction industry", 55-56 (2005)

5. E. N. Pokrovskaya, Preservation of monuments of wooden architecture with the help of organoelement compounds (2009)

6. E. N. Pokrovskaya, Chemical and physical basis for increasing the longevity of wood (2003)

7. V.I. Roldugin, Physicochemistry of the surface (2011)

8. A.S. Tutygin, A.A. Shinkaruk, A.M. Aisenstadt, V.S. Lesovik, J. of International Scientific Publications: Ecology \& Safety, 8, 54-61 (2014)

9. A.S. Tutygin, A.A. Shinkaruk, A.M. Aisenstadt, M.F. Frolova, T.A. Pospelova., J. of International Scientific Publications: Ecology \& Safety, 7, 37-45 (2013)

10. A.M. Aisenstadt, Innovative materials and technologies for construction in extreme climatic conditions, 244 (2014) 
11. B.V. Deryagin, I.I. Abrikosova, E.M. Lifshits, Successes in physical sciences, 3, 494$526(1958)$

12. B.V. Deryagin, N.V. Curaev, Wetting membranes (1984)

13. P. Dzh. Gudkh'yu, Practical Methods in Electron Microscopy (1980)

14. Dzh. Gouldsteyn Practical raster microscopy (1978)

15. B.A. Kalin, Raster electron microscopy. Laboratory work (2008)

16. A.A. Abramzon, L.Ye. Bobrova, L.P. Zaychenko, Surface phenomena and surfaceactive substances: handbook (1984)

17. A.S. Vyacheslavov, Ye.A. Pomerantseva, Measurement of surface area and porosity by the method of capillary nitrogen condensation (preparation of masters - operators of modern scientific equipment): Methodological development (2006)

18. YU.A. Podkamennyy, A.A. Nosenko Innovative method for determining the specific surface area of disperse systems and porous materials. Available at: http://conf.sfukras.ru/sites/mn2013/section060.html (2013)

19. Interstate Standard 53292-2009. Fire protection compounds and substances for wood and materials based on it. General requirements. Test methods (2007)

20. Interstate Standard 12.1.044-89*. Occupational safety standards system. Fire and explosion hazard of substances and materials. Nomenclature of indices and methods of their determination (1989)

21. N.V. Kel'tsev Basics of adsorption technique (1984)

22. S. Greg, K. Sing Adsorption. Specific surface area. Porosity (1984)

23. D. Ruthven Principles of Adsorption and Adsorption Processes (1984) 